\title{
Repensando o Papel da Universidade no Século XXI: Demandas e Desafios $^{1}$
}

\author{
Rethinking the Role of the University in the 21st Century: Demands and \\ Challenges
}

\author{
Ana Maria Nunes Gimenez ${ }^{2}$ \\ Maria Beatriz Machado Bonacelli ${ }^{3}$
}

\section{RESUMO}

O artigo trata da origem, modelos e missões da universidade, analisando aspectos relevantes do desenvolvimento dessa instituição ao longo da história, sua trajetória e as transformações pelas quais passou. Com amparo em referencial teórico da área da Educação Superior e da Política de C\&T, pretendeu-se criar um pano de fundo para uma reflexão sobre o papel universidade no século XXI, especialmente a partir das contradições evidenciadas pelo estreitamento da sua relação com a sociedade e da demanda por contribuição mais efetiva e de curto prazo para o desenvolvimento socioeconômico. Inicialmente, é possível constatar que tais desafios são enfrentados por universidades de diversos países, dado que trata-se de um fenômeno que tem ocorrido em nível mundial, o que requer que cada universidade encontre o modelo institucional mais adequado ao seu contexto, aos seus propósitos e à realidade política, econômica e social do país ao qual pertence, para que contribua de maneira mais efetiva com a sociedade.

Palavras-chave: Universidade do século XXI. Modelos e Missões. Política de C\&T.

\begin{abstract}
The article deals with the origin, models and missions of the university, analyzing relevant aspects of the development of this institution throughout history, its path and transformations through which it passed. With support in theoretical area of Higher Education and Policy $S \& T$, it is intended to create a background for a reflection on the role university in the twenty-first century, especially from the contradictions highlighted by narrowing its relationship with society and demand for more effective contribution and short-term socioeconomic development. Initially, it is clear that such challenges are faced by universities in different countries, since it is a phenomenon that has occurred worldwide, which requires that each university find the institutional model best suited to their context, their purposes and the political, economic and social development to which it belongs, to contribute more effectively to society.
\end{abstract}

Keywords: 21st Century University. Models and Missions. S\&T Policy.

\footnotetext{
1 Trabalho apresentado no dia 18 de outubro de 2013, no Grupo de Trabalho 6 - Gestão da Tecnologia e Inovação nas Universidades Latinoamericanas.

2 Departamento de Política Científica e Tecnológica (DPCT), Instituto de Geociências (IG), Universidade Estadual de Campinas (Unicamp). E-mail: anamarianunesgimenez@gmail.com

3 Departamento de Política Científica e Tecnológica (DPCT), Instituto de Geociências (IG) - Universidade Estadual de Campinas (Unicamp). E-mail: bia@ige.unicamp.br
} 


\section{INTRODUÇÃO}

O futuro da universidade não pode ser entendido sem que se compreenda o seu passado, bem como as transformações pelas quais a instituição passou ao longo do seu processo evolutivo. Diante disso, afirma-se que o estudo das diferentes concepções acerca do papel e das missões da universidade auxilia o entendimento de que tal instituição, desde o seu surgimento, na Idade Média, até a atualidade, tem ocupado um papel central na sociedade. Aparecendo em diferentes graus, a comunidade, a universalidade e a imunidade ${ }^{4}$, seus traços característicos, são responsáveis pelo estabelecimento da ideia de universidade. Características estas que, mesmo em face da evolução e das transformações sofridas ao longo dos séculos, ainda estão presentes nas universidades contemporâneas. Dessa forma, "dentro de uma linha de orientação que conserva sempre elementos comuns na instituição, as concepções de universidade variam de acordo com as sociedades em que elas se iniciam e segundo a época em que elas foram elaboradas" (JANNE, 1981, p. 28). Considera-se também, que "a universidade é um microcosmo que exprime como os conhecimentos e a cultura se acham integrados numa dada sociedade e em função de que fins" (JANNE, 1981, p. 40).

Diante disso, a hipótese que se sustenta é que o modelo institucional define a forma como as missões serão conduzidas, mas também, que o surgimento de novas missões provoca crises internas, suscitando a necessidade de redefinições e de se repensar a forma como a universidade contribuirá com a sociedade e com o desenvolvimento socioeconômico.

Portanto, com o intuito de contribuir para evolução das discussões sobre o futuro da universidade, o presente artigo tem como objetivo a compreensão de aspectos mais específicos do desenvolvimento das universidades, a partir de uma revisão de literatura que amparou-se em referencial teórico da área da Educação Superior e da Política de C\&T. Estas questões serviram de pano de fundo para uma reflexão sobre as missões da universidade e sobre os novos desafios impostos à Universidade no século XXI, a partir das contradições evidenciadas pelo estreitamento da sua relação com a sociedade, especialmente no que se refere à incorporação de políticas mais assertivas para a promoção da inovação, bem como

\footnotetext{
${ }^{4} \mathrm{O}$ que alguns autores chamam de autonomia.
} 
sobre o embate entre o prestígio acadêmico e os valores que vêm se apresentando como socialmente relevantes.

\section{CONCEPÇÕES OU MODELOS DE UNIVERSIDADE}

Pizzitola (1986) explica que são três os modelos clássicos de universidade, dos quais se originaram todos os modelos atualmente existentes: o prussiano, o napoleônico e o anglo-saxônico. Afirma-se também que os elementos constitutivos destes modelos são: o Estado, a sociedade civil e a autonomia da comunidade acadêmica. O que se sustenta, portanto, é que esses elementos representam as bases sobre as quais foram erigidas as universidades contemporâneas. A prevalência do Estado deu origem ao modelo napoleônico, a prevalência da sociedade civil, ao modelo anglo-saxônico e, finalmente, a prevalência da autonomia interna e externa fez nascer o modelo alemão ou prussiano de universidade (PIZZITOLA, 1986).

Convém observar que em 1966, na obra intitulada "Concepções da Universidade", Drèze e Debelle criaram uma sistematização que até hoje é utilizada (por meio de releituras e de "reformulações") pelos estudiosos dos tipos ou modelos de universidade. Tal sistematização tratou de agrupar os tipos de universidades sob duas concepções, as idealistas e as utilitaristas, que compreendem modelos de universidades (a alemã, a napoleônica, a inglesa, a norte-americana e a soviética). Neste estudo, além dos três modelos mencionados por Pizzitola (1986), apresentase também o modelo norte-americano, já que notou-se que esses quatro modelos aparecem na sistematização de Drèze e Debelle e são comumente mencionados nos textos que discutem a temática. Optou-se pela não apresentação do modelo soviético, pois concorda-se com a posição de alguns autores que o entendem como uma adaptação do modelo napoleônico. Assim, de acordo com a prevalência de uma ou de outra base deu-se início a um modelo institucional diferente. Portanto, o Quadro que segue apresenta uma síntese dos quatro modelos, a partir da junção dos pontos de vistas de diferentes autores. 


\begin{tabular}{|c|c|l|}
\hline MODELO & PAÍS & \multicolumn{1}{c|}{ CARACTERÍSTICAS } \\
\hline Prussiano & Alemanha & $\begin{array}{l}\text { Universidade de pesquisa: a universidade vista como uma comunidade } \\
\text { de pesquisadores; missões - ensinar e "fazer ciência"; para conduzir um } \\
\text { projeto nacional; colaboração; interdisciplinaridade, autonomia interna e } \\
\text { externa. }\end{array}$ \\
\hline Napoleônico & França & $\begin{array}{l}\text { Universidade do Estado: monopólio da instrução pública; para garantir a } \\
\text { estabilidade política; educação padronizada, uniforme; rigidez e } \\
\text { hierarquização da estrutura administrativa, ensino profissionalizante. }\end{array}$ \\
\hline $\begin{array}{c}\text { Anglo- } \\
\text { saxônico }\end{array}$ & Inglaterra & $\begin{array}{l}\text { Universidade do espírito: educar mentes; “liberal arts"*; saber universal, } \\
\text { sem fins práticos; para a elite; formação moral, intelectual e não } \\
\text { profissional ou vocacional. }\end{array}$ \\
\hline $\begin{array}{c}\text { Utilitarista } \\
\text { norte- } \\
\text { americano }\end{array}$ & EUA & $\begin{array}{l}\text { Universidade pragmática: o saber como um instrumento para a ação; } \\
\text { princípios democráticos; acesso franqueado a todos (elite e massas); a } \\
\text { serviço do desenvolvimento da nação; ensino e pesquisa a serviço do } \\
\text { estímulo à criatividade e à inovação. Originou-se do modelo anglo- } \\
\text { saxônico, mas distanciou-se deste e apresenta características bastante } \\
\text { distintas, o que requer que seja examinado separadamente. }\end{array}$ \\
\hline
\end{tabular}

Quadro 1 - Modelos Clássicos de Universidade

Fonte: elaboração própria a partir de Freitas Neto (2011); Felix (2008); Prota (1987); Pizzitola (1986); Drèze e Debelle (1983); Janne (1981).

Nota: Eram sete e estavam divididas em dois grupos de disciplinas: o trivium, que abrangia a lógica, a gramática e a retórica; e o quadrivium, com a aritmética, a música, a geometria e astronomia (CHARLE; VERGER, 1996).

O termo "prevalência" é utilizado justamente porque os elementos (Estado, sociedade civil, autonomia) nunca aparecem de forma isolada e o enfraquecimento de um, em detrimento de outro, ou a presença desequilibrada afetaria os rumos e comprometeria o futuro da universidade (por exemplo, a presença excessiva do Estado, como ocorreu no modelo napoleônico, comprometeu a autonomia e o protagonismo da comunidade acadêmica). (PIZZITOLA, 1986).

\section{A ORIGEM DA UNIVERSIDADE: MISSÃO INICIAL}

Tendo apresentado as bases que conformaram os modelos clássicos de universidades, é necessário então, tratar do surgimento destas. Assim sendo, considera-se que as primeiras universidades foram concebidas para desempenhar o papel de guardiãs e transmissoras da cultura, de repositórios do conhecimento. $O$ seu desenvolvimento histórico ocorreu entre os séculos XI e XVIII e a missão primordial era o ensino, sendo que durante todo esse período existiram para atender exclusivamente a esses propósitos (ETZKOWITZ, 2001; SAVIANI, 2009). É importante observar que a universidade medieval era conservadora, já que: 
Tratava-se mais de conservar um patrimônio de verdades do que ir à sua procura. Isso quanto ao conteúdo. Quanto à vida institucional, a universidade também não podia deixar de ser conservadora, até mesmo como atitude de "legítima defesa corporativa". Essa defesa de prerrogativas levou a universidade a considerar-se como "extraterritorial", não subordinada aos poderes locais, regionais, nacionais. A criticidade universitária tinha um limite que era a defesa de seu próprio poder ante os poderes circundantes. Mas não havia a ideia de um "papel" da universidade diante da sociedade, de "serviços" a serem prestados à comunidade extramuros (CASTANHO, 2000, p. 24).

Nos anais da história do surgimento da universidade consta que foi no final do século XI, em 1088, que começou a ser configurada aquela que é considerada a mais antiga do mundo ocidental, a Universidade de Bolonha. Concebida para ser uma instituição "leiga, não clerical, especializada na área de Direito" (CASTANHO, 2000, p. 17). Sua missão inicial era interpretação e ensino do Direito, pelos mestres de gramática, retórica e lógica da época (UNIVERSITÀ DI BOLOGNA, 2013). A universidade nasceu como uma corporação de alunos e com o passar do tempo o poder começa a ser partilhado entre alunos e professores, passando a se constituir em uma universitas alumnorum et magistrorum - "corporação de alunos e professores" (ROSSATO, 2006, p. 81).

A segunda mais antiga é a Universidade de Paris, surgida no século XII, entre os anos de 1150 e 1170, aproximadamente, tendo se notabilizado pelos estudos teológicos (SAVIANI, 2009; CASTANHO, 2000). Afirma-se que o propósito da Universidade de Paris era o oferecimento de "studium generale ou studia generalia - estudos gerais, isto é, abrangia praticamente todos os domínios do saber da época" (ROSSATO, 2006, 81). A instituição desempenhou um importante papel como uma Universidade de Teologia, tendo atuado em diversas questões da Igreja Católica. Com o advento da Revolução Francesa houve a extinção da universidade, que mais tarde ressurgiu sob o controle do Estado (ROSSATO, 2006). O modelo que surgiu é conhecido como modelo napoleônico, cujas finalidades principais eram: (i) a manutenção da estabilidade política do Estado por meio da formação de uma elite de dirigentes; (ii) ausência de autonomia; (iii) hierarquia administrativa; (iv) programas de ensino uniformes; (v) o oferecimento de ensino profissionalizante; (vi) fragmentação da estrutura a partir da criação de escolas superiores isoladas (DREZE e DEBELLE, 1983).

Nos séculos seguintes ao do surgimentos das primeiras universidades (em Bolonha e Paris) surgiram diversas universidades pela Europa. Entre as 
universidades europeias consideradas as mais célebres surgidas entre os séculos XIII e início do século XV estão: de Pádua (1222); de Nápoles (1224); de Salamanca (1218); de Siena (1240); de Oxford (1249); de Cambridge (1284); de Coimbra (1290); de Pisa (1343); de Praga (1348); de Cracóvia (1364); de Viena (1365); de Heidelberg (1386); de Colônia (1388); de Leipzig, (1409); de Louvain (1425); de Tübingen (1477); de Barcelona (1450); de Copenhague (1479); de Valência (1501); de Sevilha $(1505)^{5}$.

\section{PRIMEIRA REVOLUÇÃO ACADÊMICA: SEGUNDA MISSÃO}

Foi apenas com a criação da Universidade de Berlim, hoje conhecida como Universidade Humboldt de Berlim, que se deu início à Primeira Revolução Acadêmica, aquela que agregou uma nova missão, a pesquisa, e que deu origem a um novo modelo de universidade (PROTA, 1987). Esse novo modelo é conhecido como prussiano ou idealista alemão.

A Universidade de Berlim foi fundada em 1810, por Wilhelm von Humboldt, que foi fortemente influenciado pelas ideias reformistas do filósofo Johann Gottlieb Fichte (convidado por Humboldt para ser o primeiro reitor da Universidade) e do filósofo e teólogo Friedrich Schleiermacher. Humboldt e um grupo de contemporâneos eminentes, como o filósofo Georg Wilhelm Friedrich Hegel, o jurista Friedrich Carl von Savigny e Christoph Wilhelm Friedrich Hufeland, médico e cientista, propugnavam pela independência da academia, pela educação integral humanista, a partir da integração entre as ciências naturais, sociais e humanas, bem como pela unidade entre o ensino e a pesquisa (HUMBOLDT-UNIVERSITÄT ZU BERLIN, 2013). Na época em que Humboldt concebeu a ideia de uma instituição que além do ensino também realizasse pesquisa, eram as academias de ciência e de arte as detentoras das atividades de geração de conhecimento. Diante disso, no texto intitulado "Sobre a Organização Interna e Externa das Instituições Científicas Superiores em Berlim", Humboldt escreveu o seguinte:

\footnotetext{
${ }^{5}$ Castanho (2000) indica essas universidades como sendo as mais célebres do período. No entanto, observou-se que existe alguma divergência entre autores acerca do ano de surgimento de algumas universidades. Portanto, foram realizadas buscas diretamente nos wesites das universidades para encontrar informações mais precisas.
} 


\begin{abstract}
Geralmente denominamos instituições científicas superiores as universidades e as academias de ciência e de arte. [...] E cabe também indagar qual pode ser o alcance das atividades tanto das academias quanto das universidades. [...] Em relação à universidade, seria injusto limitá-la ao ensino e à divulgação da ciência, como se a produção de novos conhecimentos somente coubesse às academias. Na Alemanha, as ciências foram muito mais desenvolvidas por professores universitários do que por membros de academias. E os professores universitários avançaram em suas áreas de conhecimento precisamente devido à atividade docente (HUMBOLDT, 2003, p. 91-92).
\end{abstract}

A ideia de universidade compreendia a realização de duas tarefas essenciais: "de um lado, promoção do desenvolvimento máximo da ciência, de outro, produção do conteúdo responsável pela formação intelectual e moral" (HUMBOLDT, 2003, p. 78). Humboldt acreditava que as duas missões não eram antagônicas, pelo contrário, eram complementares e indissociáveis. Aliás, o contato com os estudantes, as discussões realizadas em sala de aula, os estudos, seminários em geral, conduzidos pelos docentes, eram vistos como uma rica e valiosa fonte para a atividade de pesquisa. Esta, por sua vez, contribuía não somente para o avanço da ciência, como também para a melhoria da missão ensino, ou seja, uma alimentava a outra, sendo, portanto, uma via de mão dupla (HUMBOLDT, 2003). Assim, percebese que a partir da agregação de uma nova missão deu-se início a um novo modelo, conhecido como modelo prussiano ou idealista alemão, que logo ganhou adeptos, em diversas partes do mundo, no decorrer do século XIX. Afirma-se que durante esse percurso evolutivo a universidade se manteve fiel à missão original, o ensino, mas alterou a sua estrutura e competência para incorporar a missão pesquisa (GÖRANSSON, MAHARAJH E SCHMOCH, 2009).

A partir da primeira revolução acadêmica, a universidade incorpora uma nova missão em decorrência de demandas que surgiram da própria condução da missão anterior. Isso pode ser entendido com um processo natural e como resultado da própria evolução do papel da universidade. Assim, o contexto do desenvolvimento científico e tecnológico e das alterações na sociedade forçaram e continuarão forçando as universidades a revisarem as suas práticas de ensino, formas de interação com o seu em torno, entre outras. Diante desses argumentos, afirma-se que a continuidade da universidade reside na sua própria história de desenvolvimento (ETZKOWITZ, 2001). 


\section{SEGUNDA REVOLUÇÃO ACADÊMICA: TERCEIRA MISSÃO}

Entende-se que apesar da tensão que marca a inserção social da universidade, "ela é uma instituição social e se amolda às diferentes configurações sociais registradas na história" (CASTANHO, 2000, p. 23). Da mesma forma como foram drasticamente alterados os modos de produção, a conformação da sociedade, entre outros, a universidade também sofreu profundas alterações desde a sua concepção, e isso não poderia ser diferente, tendo em vista que ela também é um instituição social e não está imune às transformações que ocorrem no seio da sociedade. Diante disso, afirma-se que:

A dupla abertura da universidade - à pesquisa, pelo exercício da razão
humana num primeiro momento e pela experimentação, num segundo, e à
sociedade, cujo destino passa a lhe interessar - vai marcar profundamente
a vida dessa instituição a partir da Renascença, culminando em construções
práticas e formulações teóricas nos séculos XIX e XX (CASTANHO, 2000,
p. 24).

Etzkowitz e Leydesdorff (1997) explicam que ainda no século XIX, a universidade já começava a se deparar com a necessidade de realizar mais uma transição importante, quando se começa a reconhecer a importante função social desempenhada pelo ensino superior e a grande contribuição que este poderia trazer à sociedade, dando origem à ideia de uma terceira missão.

A terceira missão tem sido tipicamente concebida como um conjunto de funções que são consideradas distintas das funções ensino e pesquisa (VORLEY; NELLES, 2008). Nesse campo, há os que focam mais na função empreendedora da universidade e da necessária relação desta com indústria, o governo, bem como o enquadramento dos sistemas de inovação em nível nacional, regional e mundial, como é o caso do modelo da Hélice Tripla, defendido por Etzkowitz e Leydesdorff em diversos trabalhos. Afirma-se que é necessário, cada vez mais, que ocorra a interação entre a universidade, indústria e governo, bem como a reconfiguração do contrato social entre a universidade e a sociedade em geral, tendo em vista que o financiamento público (da universidade) está, cada vez mais, subordinado a uma contribuição mais direta desta para o desenvolvimento econômico. Assim, defendese que a concretização da terceira missão da universidade passa pela atuação efetiva no desenvolvimento, para além das suas missões tradicionais, fomentando as atividades de inovação e de capitalização do conhecimento (ETZKOWITZ; 
LEYDESDORFF, 1997).

No entanto, sustenta-se que a terceira missão pode envolver muitas das demandas crescentes que se colocam para a universidade, principalmente porque embaixo desse grande "guarda-chuva" é possível abrigar todas aquelas ações que não são cobertas pelas duas missões anteriores, ou seja, o ensino e a pesquisa. No entanto, entende-se também, que é justamente essa função residual que tem dificultado o entendimento ou o consenso acerca do que seja realmente a terceira missão, bem como do seu alcance, o que torna o conceito um tanto vago ou genérico (GÖRANSSON, MAHARAJH E SCHMOCH, 2009). Vorley e Nelles (2008) entendem que a terceira missão deve, antes de tudo, reforçar a capacidade de conexão interna, se apresentando como uma oportunidade para o desenvolvimento institucional, para além das atividades de patenteamento e de transferência de tecnologia. Isso quer dizer que a terceira missão deve contribuir para que a universidade repense e redefina o seu papel, para reforçar e consolidar as missões centrais (ensino e pesquisa) e a para que estabeleça a forma como pretende contribuir para o desenvolvimento socioeconômico. Os autores consideram que estes são os grandes desafios que se colocam para a universidade contemporânea.

Discutiu-se neste trabalho, que novos modelos têm sido propostos para orientar a evolução das universidades, tais como o da Hélice Tripla, como mencionado anteriormente, ou a criação de novos modelos de universidades (empresariais ou especializadas), por exemplo, para dar conta de novas demandas que se colocam para a universidade contemporânea. Sustenta-se, entretanto, que o mais importante disso tudo é que a ideia de uma terceira missão deve servir para orientar a universidade no sentido de assumir maior visibilidade e estimular o uso do conhecimento gerado internamente para o desenvolvimento social, cultural e econômico (GÖRANSSON, MAHARAJH E SCHMOCH, 2009) e, mais fortemente, para o desenvolvimento inovativo, internalizando demandas das políticas de ciência, tecnologia e inovação que se tornam cada vez mais explícitas - assunto a ser explorado em outra ocasião. 


\section{CONSIDERAÇÕES FINAIS}

Conforme apresentado, é na Idade Média que encontramos a gênese da universidade, criada para ser a guardiã e transmissora do conhecimento já existente e que atendia a demandas individuais, sem se preocupar com o seu entorno, com o seu papel na sociedade, nem com os serviços que poderia prestar-Ihe. A universidade nasce elitista e se apresenta ora de caráter público ou privado, ora ligada à Igreja ou ao Estado, ora preocupada com uma formação moral e intelectual do indivíduo ou oferecendo treinamento especializado para um ofício, ora preocupada com desenvolvimento máximo da ciência. Essa instituição passou por inúmeras transformações ao longo dos séculos, assim como o próprio contexto econômico, político e social. Portanto, não era de se esperar que a universidade passasse incólume pelas drásticas alterações ocorridas na sociedade. Também, não se pode esperar que a universidade não continue evoluindo e não responda às novas demandas que têm sido criadas.

É sabido que a Universidade tem sido chamada a promover a inclusão social, a dialogar com o setor produtivo, a reformular as suas grades curriculares, a criar novos cursos, a estreitar mais os laços com a sociedade em geral e a participar mais ativamente do desenvolvimento econômico. Percebe-se, portanto, que a universidade contemporânea tem se deparado com diferentes demandas e isso a tem forçando a repensar e a redefinir o seu papel, em busca de um "modelo" que dê conta das suas missões, bem como de expectativas da sociedade. Então, entra em cena a ideia de uma terceira missão.

Dessa forma, além da formação de massa crítica, a universidade do século XXI tem sido instada a se envolver em atividades empreendedoras e a fomentar benefícios sociais. Percebe-se, portanto, que a incorporação de uma terceira missão requer a realização de inovações institucionais e a criação de estratégias voltadas à consolidação de políticas explícitas nesse campo, sem, no entanto, sobrecarregar a universidade e de uma forma que as missões não se sobreponham, pelo contrário, que sejam complementares, que se retroalimentem. Nota-se que esses desafios são um fenômeno mundial e que as soluções não podem ser universais, pelo contrário, cada país, cada região, cada universidade, deverá encontrar o modelo mais adequado à sua realidade e aos seus propósitos. 


\section{REFERÊNCIAS}

CASTANHO, S. E. M. A universidade entre o sim, o não e o talvez. In: VEIGA, I. P. A., CASTANHO, Maria Eugênia L. M. (Orgs.). Pedagogia universitária: a aula em foco. Campinas, SP: Papirus, 2000, p. 13-48.

CHARLE, C.; VERGER, J. História das universidades. Tradução de Élcio Fernandes. São Paulo, SP: UNESP, 1996.

DRÈZE, Jacques H.; DEBELLE, Jean. Concepções da Universidade. Tradução Francisco de Assis Garcia e Celina Fontenele Garcia. Fortaleza: UFC, 1983.

ETZKOWITZ, H.; LEYDESDORFF, L. Introduction: Universities in the Global Knowledge Economy. In: ETZKOWITZ, H.; LEYDESDORFF (orgs). Universities in the Global Knowledge Economy - A Triple Helix of University-IndustryGovernment Relations. London: Pinter, 1997, p. 1-8.

ETZKOWITZ, Henry. The Second Academic Revolution and the Rise of Entrepreneurial Science. IEEE Technology and Society, v. 20, Issue 2 (Summer) p.18-29, 2001.

FELIX, G. T. Reconfiguração dos modelos de universidade pelos formatos de avaliação: efeitos no Brasil e Portugal. 2008. Tese (Doutorado em Educação), Universidade Federal do Rio Grande do Sul, Faculdade de Educação, Porto Alegre, RS: [s.n.], 2008.

GÖRANSSON, B.; MAHARAJH, R.; SCHMOCH, U. Introduction: New challenges for universities beyond education and research. Science and Public Policy, 36(2), p. 83-84.

HUMBOLDT-UNIVERSITÄT ZU BERLIN. Short History. 2013. Disponível em: $<$ http://www.hu-berlin.de/ueberblick-

en/history/huben_html/huben_html?set_language=en\&cl=en>. Acesso em: 20 mai. 2013.

HUMBOLDT, W. Sobre a organização interna e externa das instituições científicas superiores em Berlim. In: CASPER, G.; HUMBOLDT, W. Um mundo sem universidades? Rio de Janeiro: EdUERJ, 2003.

JANNE, Henri. A universidade e as necessidades da sociedade contemporânea. Tradução de Invanova dos Santos Dias Soares. Fortaleza: Ed. UFC, 1981.

PIZZITOLA. A. Autonomia e "necessità" alle origini dele Università contemporanee. In: DE VIVO, F.; GENOVESI, Giovanni (a cura di). Cento anni di universita: I'istruzione superiore in Italia dall'unita ai nostri giorni: atti del III Covegno Nazionale (Padova, 9-10 novembre 1984). Napoli: Scientifiche, 1986. 310p. (Frontiere dell'educazione; v. 1). p. 137-146.

PROTA, Leonardo. Um novo modelo de universidade. São Paulo: Convívio, 1987. 
ROSSATO, R. Universidade de Paris. In: MOROSINI, M. F. (Org.). Enciclopédia de pedagogia universitária: Glossário. Brasília: INEP, 2006. v. 2., p. 81.

. Universidade de Bolonha: In: Enciclopédia de pedagogia universitária: Glossário. Brasília: INEP, 2006. v. 2. p. 81.

SAVIANI, D. O Futuro da Universidade entre o Possível e o Desejável. Estudos Avançados, Campinas, set. 2009, p. 1-9. Disponível em:

<http://www.gr.unicamp.br/ceav/revista/content/pdf/O_futuro_da_universidade_Derm eval_Saviani.pdf>. Acesso em: 18 abr. 2013.

VORLEY, T.; NELLES, J. (Re)Conceptualising the Academy: Institutional Development of and beyond the Third Mission. In: Higher Education Management and Policy, v. 20, n. 3, Paris: OCDE, 2008, p. 119-131. 